\title{
How Precise and Accurate Can Mg Isotope Data Be by Using the Sample- Standard Bracketing Method?
}

\author{
FANG HUANG $^{1}$, WENYU WANG ${ }^{2}$ AND JINTING KANG ${ }^{2}$
}

${ }^{1}$ CAS Key Laboratory of Crust-Mantle Materials and Environments, School of Earth and Space Sciences, University of Science and Technology of China

${ }^{2}$ University of Science and Technology of China

Presenting Author: fhuang@ustc.edu.cn

$\mathrm{Mg}$ isotopes have been widely applied to study a number of fundamental geochemical processes such as planet formation, mantle-crust differentiation, and continent weathering. Although equilibrium $\mathrm{Mg}$ isotope fractionation at high temperature could be small $(<0.1 \%)$, such fractionation is still important for understanding the planet accretion and magmatism. High quality $\mathrm{Mg}$ isotope data are urgently required to elucidate the hightemperature processes.

Sample-standard bracketing method (SSB) is the most common technique for $\mathrm{Mg}$ isotope analyses. The sample solutions are bracketed by pure Mg standards (such as DSM-3) to correct the instrumental mass bias in MC-ICP-MS. Two standard deviations (2SD) for $\delta^{26} \mathrm{Mg}$ using such method are normally 0.05 to $0.10 \%$, not enough to reveal the small fractionation the high temperature geochemistry processes. Using two standard errors $(2 \mathrm{SD} / \sqrt{ } \mathrm{N})$ may underestimate the analytical uncertainties if the number of analyses $(\mathrm{N})$ is small, while $2 \mathrm{SD}$ may over-estimate the uncertainties.

For a better denotation of the error for $\mathrm{Mg}$ isotopes using the SSB method, we first evaluated the analytical uncertainty calculation and show that tSE (Students'T * standard error) is better to represent the $95 \%$ confidence interval than $2 \mathrm{SD}$ and 2SE. Second, we determined the optimal number of measurements to obtain a small tSE based on the current instrumental conditions. Third, we increased the concentration of the measured solution for a higher signal/noise; and finally, we measured a series of solutions doped with different $\delta^{26} \mathrm{Mg}$ to identify the tiny isotope variation.

The results show that the 2SD of the measurement can be improve from $0.05 \%$ to $0.04 \%$ when increasing the $\mathrm{Mg}$ contents in running solution from $0.8 \mu \mathrm{g} / \mathrm{g}$ to $1.2 \mu \mathrm{g} / \mathrm{g}$. Because the tSE can approach to $0.02 \%$ o $(\mathrm{N}=6)$, an offset of $0.03 \%$ between the doped and un-doped solutions was well resolved by six-time's bracketing. Therefore, our method can detect the small fractionation of $\mathrm{Mg}$ isotopes in the high-temperature processes such as collisional evaporation during the Earth accretion, melting and metasomatism of the mantle, and fractional crystallization during magmatism. In addition, the principles of this method can be used to analyze other isotopes such as $\mathrm{Li}, \mathrm{Si}$, $\mathrm{Fe}$, and $\mathrm{V}$. 